DOI 10.17816/transsyst201843s1264-271

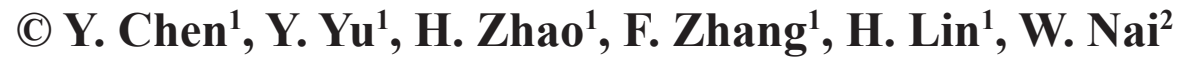

${ }^{1}$ Tongji University

(Shanghai, China)

${ }^{2}$ Tongji Zhejiang College

(Jiaxing, China)

\title{
DATAFLOW ANALYSIS OF VEHICLE SAFETY COMPUTERS REGARDING HIGH-SPEED MAGLEV TRANSPORTATION BASED ON DATA PRIORITIES
}

To analyze the dataflow of vehicle safety computers regarding high-speed maglev transportation, it is considerable to add data priorities to the dataflow model of vehicle safety computers to improve the accuracy. With regard to vehicle safety computers, we choose VSC1 as our research object. First, we give a brief summary for the interface relationships of VSC1. Next, we analyze the data priorities of VSC1 in detail. After that, we present the dataflow model of VSC1 with priorities. Finally, we make a brief conclusion. The structure of the abstract of an article is strictly arranged and should encompass the following points:

Background: Dataflow model of Vehicle Safety Computers regarding high-speed maglev transportation.

Aim: To analyze the dataflow of vehicle safety computers with data priorities.

Methods: interface analysis, data priority analysis and dataflow chart.

Results: The dataflow model of VSC1 with data priorities is presented.

Conclusion: Adding data priorities to the dataflow model of vehicle safety computers to improve the accuracy is fulfilled. The recommended number of words in the abstract is 500 .

Keywords: high-speed maglev; vehicle safety computer; dataflow; data priority, inteface analysis, dataflow accuracy, ATP

\section{INTRODUCTION}

Vehicle safety computers (VSCs) are the onboard part of the operation control system (OCS) regarding high-speed maglev and responsible for control and safety protection for maglev trains. They are always located at two sides of maglev trains. Relative to the traditional railway signal systems, they are same as ATP (Auto Train Protection). For ATP, the software safety integrity level (SIL) of ATP function is SIL-4 [1]. In a word, vehicle safety computers are safety critical software systems, always based on embedded hardware system, and their requirement of real-time and safety are very high.

Due to the complexity of software systems and especially the importance of non-functional requirements including performance, security, or compliance with 
law increases, to ensure quality properties is hard and often shifted to the operations phase. Fixing issues found in this phase is, however, costly. The data flow analysis enables early detection of requirement violations regarding privacy laws, external service providers, and throughput requirements on the architectural level [2].

With regard to the data flow analysis of vehicle safety computers, three papers are related to this, all written by myself. In [3], the information flow is analyzed and the software architecture is designed for the vehicle control system (VCS). In [4], the information flow analyzed for the OCS. In [5], the information flow is analyzed for the forced stop management of the OCS. However, all these papers are omitted one important point that various data has various priority. To improve the accuracy of dataflow analysis for vehicle safety computers, integrating the data priority is necessary.

How to improve the accuracy of dataflow analysis, some approaches are presented by means of data priorities. In [6], the accuracy improvement of dataflow analysis for cyclic stream processing applications scheduled by static priority preemptive schedulers is presented. In [7], the temporal analysis of static priority preemptive scheduled cyclic streaming applications using CSDF models is introduced. It is worth mentioning that both papers are concerned with big data.

What are executed on vehicle safety computers are consist of dataflow processing applications which regularly contain cyclic data dependencies due to the presence of feedback loops and bounded FIFO buffers. In order to analyze the dataflow of vehicle safety computers with high accuracy improvement, it is considerable to add data priorities to the dataflow model of vehicle safety computers. Therefore, this paper presents the dataflow model with data priorities for vehicle safety computers.

\section{INTERFACE ANALYSIS OF VEHICLE SAFETY COMPUTERS}

For each of maglev trains, there are two vehicle safety computers in it. One is vehicle safety computer No.1 (VSC1), and the other is vehicle safety computer No.2 (VSC2). Both vehicle safety computers locate at two ends of a maglev train, i.e. driver's cabs. Once VSC1 loses the control to a maglev train, VSC2 can make a safety stop of the train. In others word, VSC2 is a standby of VSC1. They are slightly different in functionalities and interfaces. To simplify the dataflow for vehicle safety computers, we only choose VSC1 to analyze the interfaces and data priorities.

VSC1 has physical interfaces to vehicle electrical facilities, which are Locating Unit, Onboard Controller, Driver Console, Forced Stop Button and Braking Unit. By means of Locating Unit, VSC1 can get locating data of a maglev train, 
such as position, speed and direction. By means of Onboard Controller, VSC1 can control vehicle's doors, suspension, etc., and get their feedback. By means of Driver Console, VSC1 can receive a driver' instructions. By means of Forced Stop Button, VSC1 can get a forced stop signal once a driver push the button. By means of Braking Unit, VSC1 can active eddy-current braking unit when the speed profile is infringed.

VSC1 also has physical interface to the Radio System, which fulfill logical interface to decentralized safety computers (DSC). Fig. 1 shows the interfaces of VSC1.

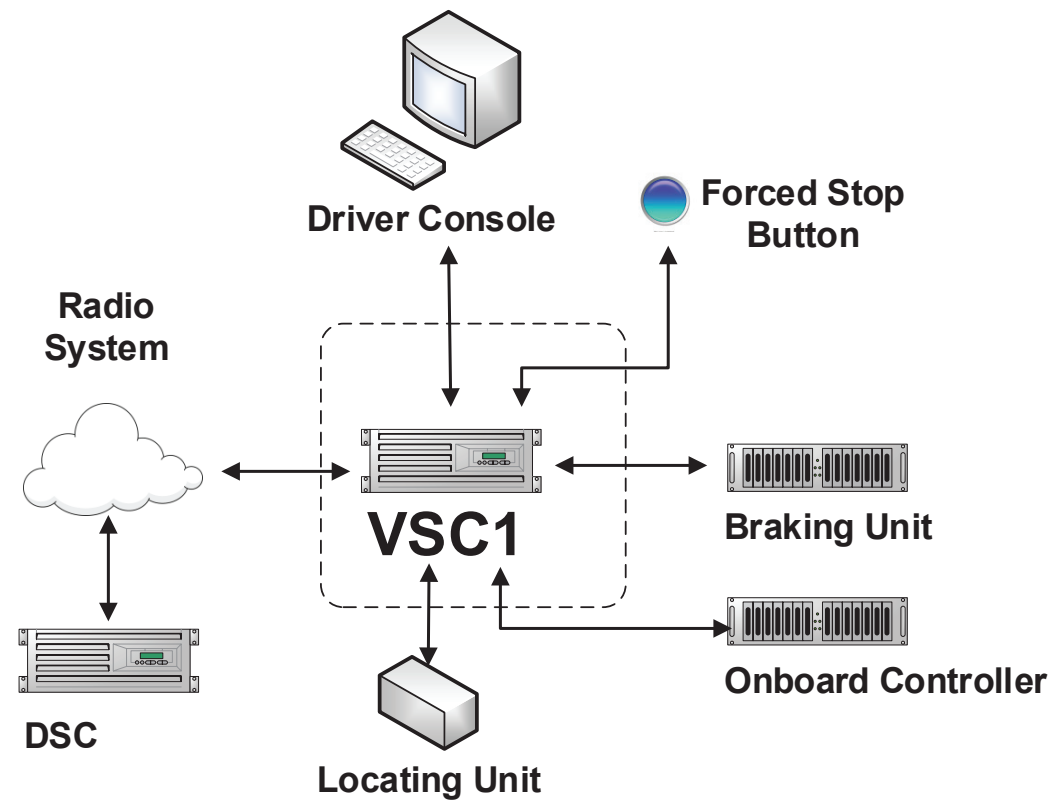

Fig. 1. The interfaces of VSC1

\section{DATA PRIORITY ANALYSIS OF VSC1}

During the processing cycle of VSC1, various data coming from different data sources may happens at the same time. Because the importance of data is different, VSC1 should distinguish the data priority so that it can process the most important data first.

Table 1 gives the complete analysis of data priorities for VSC1.

\section{DATAFLOW ANALYSIS OF VSC1 WITH DATA PRIORITY}

VSC1 has three main function modules:

1. The Safety Locating module: It receives location data from Locating Unit and generates safety location data. In the meantime, it maintains a storage area to 
Table 1. Data Priorities Analysis of VSC1

\begin{tabular}{|c|c|c|c|}
\hline $\begin{array}{l}\text { Interface } \\
\text { Object }\end{array}$ & $\begin{array}{c}\text { Interactive } \\
\text { Data }\end{array}$ & Data & Interface Object \\
\hline $\begin{array}{l}\text { Braking } \\
\text { Unit }\end{array}$ & $\begin{array}{l}\text { signal of } \\
\text { braking } \\
\text { level }\end{array}$ & $\begin{array}{l}\text { VSC1 } \\
\text { Braking Unit }\end{array}$ & $\begin{array}{l}\text { VSC1 outputs corresponding braking force level } \\
\text { according to the scale of over-speed. Before VSC1 } \\
\text { executes a brake, VSC } 1 \text { needs send a propulsion } \\
\text { shutoff request to the interactive DSC. The } \\
\text { processing priority is P1. }\end{array}$ \\
\hline $\begin{array}{l}\text { Locating } \\
\text { Unit }\end{array}$ & $\begin{array}{l}\text { location } \\
\text { data }\end{array}$ & $\begin{array}{l}\text { Locating } \\
\text { Unit } \rightarrow \text { VSC1 }\end{array}$ & $\begin{array}{l}\text { After receiving the location data VSC1 generates } \\
\text { safety location data. If VSC1 detects that the speed } \\
\text { profile is violated for the current stopping point, } \\
\text { VSC1 sends a request of propulsion shutoff to the } \\
\text { interactive DSC, and then sends a brake signal to the } \\
\text { Braking Unit. VSC1 also sends the safety location } \\
\text { data to the interactive DSC in order to perform } \\
\text { under-speed protection. The processing priority is P2. }\end{array}$ \\
\hline $\begin{array}{l}\text { Forced } \\
\text { Stop } \\
\text { Button }\end{array}$ & $\begin{array}{l}\text { forced stop } \\
\text { signal }\end{array}$ & $\mathrm{FS} \rightarrow \mathrm{VSC} 1$ & $\begin{array}{l}\text { After receives a forced stop signal, VSC1 performs } \\
\text { a forced stop by prohibiting stopping point stepping, } \\
\text { and the train will stopped at the current stopping } \\
\text { point. The processing priority is } \mathrm{P} 3 \text {. }\end{array}$ \\
\hline \multirow[t]{2}{*}{$\begin{array}{l}\text { Onboard } \\
\text { Controller }\end{array}$} & $\begin{array}{l}\text { vehicle } \\
\text { status }\end{array}$ & $\mathrm{OBC} \rightarrow \mathrm{VSC} 1$ & $\begin{array}{l}\text { VSC1 detects whether a forced stop signal occurs } \\
\text { which is generated by Onboard Controller. If so, } \\
\text { VSC1 implements a forced stop by prohibiting stop } \\
\text { point stepping, and the maglev train will stop at the } \\
\text { current stop point or a service station. VSC1 also } \\
\text { sends the vehicle status data the interactive DSC. } \\
\text { The processing priority is P4 }\end{array}$ \\
\hline & $\begin{array}{l}\text { vehicle } \\
\text { control } \\
\text { signals }\end{array}$ & $\mathrm{VSC} 1 \rightarrow \mathrm{OBC}$ & $\begin{array}{l}\text { By sending vehicle control signals to OBC, VSC1 } \\
\text { control the suspension, doors, etc. The processing } \\
\text { priority is P5. }\end{array}$ \\
\hline \multirow[t]{4}{*}{ DSC } & $\begin{array}{l}\text { stopping } \\
\text { point } \\
\text { stepping } \\
\text { request }\end{array}$ & VSC $1 \rightarrow \mathrm{DSC}$ & $\begin{array}{l}\text { VSC1 initiates stopping point stepping to the } \\
\text { interactive DSC to fulfill continuous operation. The } \\
\text { processing priority is P6. }\end{array}$ \\
\hline & line data & $\mathrm{DSC} \rightarrow \mathrm{VSC} 1$ & $\begin{array}{l}\text { VSC1 receives line data from the interactive DSC } \\
\text { to generate speed profiles for the following stopping } \\
\text { points. The processing priority is } \mathrm{P} 6 \text {. }\end{array}$ \\
\hline & $\begin{array}{l}\text { instructions } \\
\text { and status } \\
\text { from DSC }\end{array}$ & $\mathrm{DSC} \rightarrow \mathrm{VSC} 1$ & $\begin{array}{l}\text { DSC manages and controls VSC1 by sending } \\
\text { instructions and status data. VSC1 also sends } \\
\text { the status data o Driver Console for display. The } \\
\text { processing priority is P7. }\end{array}$ \\
\hline & $\begin{array}{l}\text { requests } \\
\text { and vehicle } \\
\text { status }\end{array}$ & $\mathrm{VSC} 1 \rightarrow \mathrm{DSC}$ & $\begin{array}{l}\text { VSC1 sends requests and vehicle status to DSC for } \\
\text { collaboration and sharing. The processing priority is } \\
\text { P7. }\end{array}$ \\
\hline \multirow[t]{2}{*}{\begin{tabular}{|l|} 
Driver \\
Console
\end{tabular}} & \begin{tabular}{|l} 
operation \\
status
\end{tabular} & $\mathrm{VSC} 1 \rightarrow \mathrm{DC}$ & $\begin{array}{l}\text { VSC1 Sends the operation status to DC for display. } \\
\text { The processing priority is P8. }\end{array}$ \\
\hline & $\begin{array}{l}\text { driver's } \\
\text { instructions }\end{array}$ & $\mathrm{DC} \rightarrow \mathrm{VSC} 1$ & $\begin{array}{l}\text { VSC1 transparently forwards driver's instructions } \\
\text { to DSC for train control in driver mode. The } \\
\text { processing priority is P8. }\end{array}$ \\
\hline
\end{tabular}


store the safety location data, such as speed, positon and direction of a maglev train. Moreover, it distributes the safety location data to the Vehicle Protection module, the Speed Profile Monitoring module, and DSC.

2. The Vehicle Protection module: It receives control instructions (such as opening doors, levitating the maglev, etc.) from DSC and send corresponding signals to Onboard Controller. Meanwhile it receives feedback from Onboard Controller and detects whether any forced stop signal occurs. In addition, it receives the forced stop signal from Forced Stop Button. Once a stop signal is detected, it sends an instruction that prohibits stopping point stepping to the Speed Profile Monitoring module. It receives driver instruction from Driver Console and transparently transmits to DSC. In the meantime, it maintains a storage area to store the vehicle status data, like status of doors, suspension of a maglev train. Moreover, it distributes the vehicle status data to the Speed Profile Monitoring module and DSC.

3. The Speed Profile Monitoring module: It is the core module of VSC1 and depends on three kind of data: safety location data from the Safety Locating

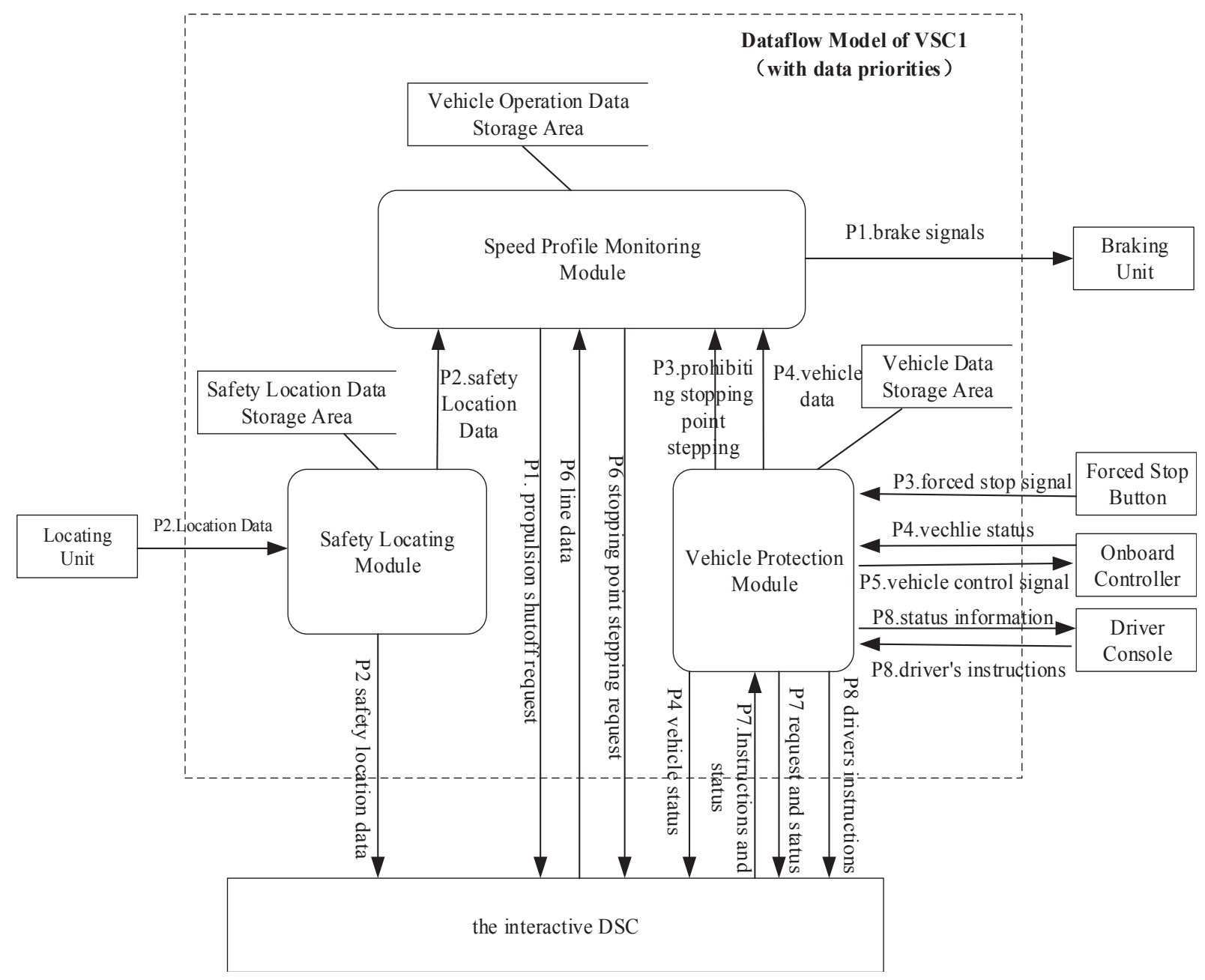

Fig. 2. The dataof VSC1 with data priorities 
module, vehicle data from the Vehicle Protection module, and line data from DSC. In the meantime, it maintains a storage area to store the operation data. It is responsible for monitoring the speed profile according to the current stopping point. When the speed profile is infringed, it actives eddy-current braking after sending a request to DSC to perform a propulsion shutoff.

According to the function modules and data priority analysis of VSC1, we present the dataflow model with data priorities as Fig. 2.

\section{CONCLUSION}

Vehicle safety computers are safety critical systems and the safety integrity level are same as ATP. If the data priority is omitted, the dataflow model for vehicle safety computers will be less accurate.

To simplify the problem for vehicle safety computers, we choose VSC1 as a representative for vehicle safety computers to analyze.

The interfaces to VSC1 include Locating Unit, Onboard Controller, Driver Console, Forced Stop Button, Braking Unit and DSC.

The various data from different interactive sources include signal of braking level, location data, forced stop signal, vehicle status, vehicle control signals, stopping point stepping request, line data, instructions and status from DSC, requests and vehicle status from VSC1, operation status and driver's instructions. Their processing priorities are assigned from $\mathrm{P} 1$ to $\mathrm{P} 8$ according to the importance analysis.

VSC1 has three main function modules: The Safety Locating module, The Vehicle Protection module and The Speed Profile Monitoring module. The three function modules of VSC1 have their dataflow and storage area respectively. According to the analysis of data priority and data process, the data flow model of VSC1 is established.

\section{ACKNOWLEDGEMENTS}

This work is supported by the National Key R\&D Program of the $13^{\text {th }}$ Fiveyear Plan, Research on Simulation Verification and Design Optimization of Key Technologies for High Speed Maglev Transportation System (No. 2016YFB120060202). This work is also supported by Fund of Shanghai Cooperative Innovation Center for Maglev and Rail Transit. 


\section{References}

1. Wang H, Gao C, Liu S. Model-based software development for automatic train protection system. Computer Engineering. 2013;1(3):463-466. doi: 10.1109/paciia.2009.5406387

2. Seifermann S. Architectural Data Flow Analysis. Proceedings of the $13^{\text {th }}$ Conference on Software Architecture (WICSA); 2016 Apr 5-8; Venice, Italy: IEEE; 2016. doi: 10.1109/ wicsa.2016.49

3. Chen Y, Zhao H, Liao Z, Yu Y. Information Flow Analysis and Software Architecture Design for the Vehicle Control System in a High-Speed Maglev Transportation System. Proceedings of the $16^{\text {th }}$ COTA International Conference of Transportation Professionals; 2016 Jul 6-9; Shanghai, China: ASCE; 2016. doi: 10.1061/9780784479896.093

4. Chen Y, Zhao H, Yu Y, Li Z. Information Flow Analysis on Operational Control Systems Regarding High-Speed Maglev Transportation. Proceedings of the $17^{\text {th }}$ COTA International Conference of Transportation Professionals; 2017 Jul 7-9; Shanghai, China: ASCE; 2017.

5. Chen Y, Zhao H, Yu Y, Li Z. Information Flow Analysis on Forced Stop Management of Operation Control System in High-Speed Maglev Transportation. Proceedings of the $17^{\text {th }}$ Cota International Conference of Transportation Professionals; 2017 Jul 7-9; Shanghai, China: ASCE; 2017.

6. Wilmanns PS, Hausmans JPHM, Geuns SJ, Bekooij MJG. Accuracy Improvement of Dataflow Analysis for Cyclic Stream Processing Applications Scheduled by Static Priority Preemptive Schedulers. Proceedings of the $17^{\text {th }}$ Euromicro Conference on Digital System Design (DSD) 2014; 2014 Aug 27-29; Verona, Italy. IEEE. doi: 10.1109/dsd.2014.69

7. Kurtin PS, Bekooij MJG. Temporal analysis of static priority preemptive scheduled cyclic streaming applications using CSDF models. Proceedings of the $14^{\text {th }}$ ACM/IEEE Symposium on Embedded Systems for Real-Time Multimedia; 2016 Oct 6-7; PA, USA. ACM. doi: 10.1145/2993452.2993564

\section{Information about the authors:}

Yijun Chen, master, senior engineer; 4800 Caoan Road, Shanghai, China;

ORCID: 0000-0001-8665-4619;

E-mail: chenyijun@tongji.edu.cn

Yi Yu, doctor, professor;

ORCID: 0000-0002-5763-4931;

E-mail: 12164@tongji.edu.cn

Huahua Zhao, master, engineer;

ORCID: 0000-0002-1210-3782;

E-mail: 12126@tongji.edu.cn

Fangqi Zhang, master, engineer;

ORCID: 0000-0002-6994-1074;

E-mail: 12176@tongji.edu.cn 
Hui Lin, bachelor, engineer;

ORCID: 0000-0003-3945-1370;

E-mail: 12124@tongji.edu.cn

Wei Nai, doctor, lecturer;

ORCID: 0000-0002-4656-7040;

E-mail: alexni@tongji.edu.cn

To cite this article:

Chen Y, Yu Y, Zhao H, et al. Dataflow Analysis of Vehicle Safety Computers Regarding HighSpeed Maglev Transportation based on Data Priorities. Transportation Systems and Technology. 2018;4(3 suppl. 1):264-271. doi: 10.17816/transsyst201843s1264-271 